\title{
Musealizar a queda
}

\section{Retaining the Fall: a museum's task}

\author{
Felipe Ribeiro'
}

DOI 10.265 I2/museologia.v9i I8.34557

\section{Resumo}

Este artigo investiga como as recentes derrubadas de estátuas de escravagistas e colonizadores pelo movimento Black Lives Matter, resvala na arte e em seus pilares institucionais. Sugiro que $o$ ativismo político, que surge do performativo da derrubada desses monumentos, tem um caráter afirmativo que, uma vez suficientemente escutado e reverberado, se torna uma virada estética na função das estátuas. Inserida nos movimentos experimentais e de vanguarda, a escultura se afasta do figurativo, rumo ao minimalismo, à escultura social, entre outras atuações, às quais Lucy Lippard e John Chandler denominaram de a desmaterialização da obra de arte. Sem nem por isso apaziguar o levante antirracista, sugiro que sua ação seja percebida também em sua potência artística, para que estremeça também as bases históricas da arte e percebamos que o que está em jogo é uma operação estética que, de forma alguma, se basta na representação identitária. Ao longo dessa proposição, me utilizo de textos e conceitos de Denise Ferreira da Silva, Achilles Mbembe, James Baldwin, entre outros. Realizo paralelamente um ensaio fotográfico de artistas brasileiros, cuja obra nos ajude a problematizar os protagonismos coloniais, racialização e o agenciamento da branquitude.

\section{Palavras-chave}

Escultura.Ativismo. Estudos decoloniais. História da arte.

\begin{abstract}
In this paper, I cling to the recent torn downs by the Black Lives Matter movement of statues of slave holders and colonialists to investigate its effects both to the arts and its institutional grounds. I suggest that the performativity of such torn downs not only consolidates a political activism but also that its affirmative nature may pose an aesthetic turn to the very representational function of statues, as we know it. Through the scope of experimental and vanguardist movements of the last century, sculpture draws back from the figurative tradition, and towards minimalism, and social sculpturing, as well as a number of other different procedures, which, hence, lead Lucy Lippard and John Chandler to denominate them as the dematerialization of the work of art. However, rather than using art theory to bring the antiracist upheavals to peace, $I$ intend to assert their investing against statues as a trembling to art history that makes us realizes the aesthetic operation at play goes further beyond identitarian representation. Throughout this proposition I rely on the writings and concepts of Denise Ferreira da Silva, Achilles Mbembe, James Baldwin, among others. In parallel, I also cast photos by Brazilian performance artists whose works raise issues regarding race, coloniality and white agency.
\end{abstract}

\section{Keywords}

Sculpture. Activism. Decolonial Studies. History of Art.

I É curador independente, artista multidisciplinar, professor do DAC/UFRJ - núcleo de dança e cinema, e professor do Programa de Pós-graduação em Dança da UFRJ.É doutor pelo PPGARTES/UERJ e mestre em Cinema Studies pela NYU. No momento é professor visitante na Roehampton onde desenvolve uma série de performances e instalações denominada Ações de Revirada. E-mail: felipekribeiro@gmail.com. ORCID: https://orcid.org/0000-0002-0199-0953. 
"Essas estátuas, funcionam como ritos de evocação de defuntos, aos olhos dos quais a humanidade negra nunca contou para nada [...]" Achilles Mbembe (2018: 227).

Figura I - Monumoments (2017), performance do Coletivo Bonobando, com Adriana Schneider e Simon Will. Trabalho comissionada para a edição AdF.crise - A Besta e o Soberano do Festival Atos de Fala.

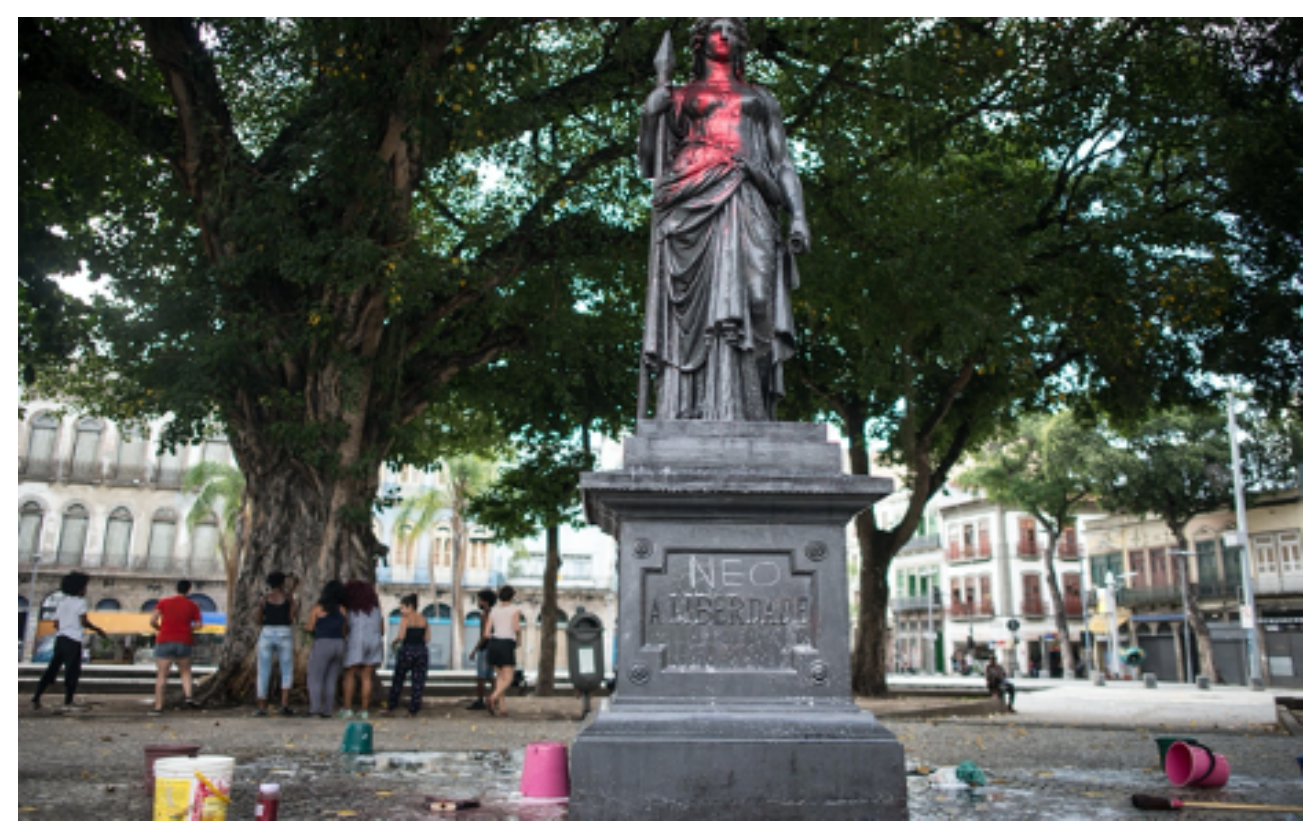

Fonte:Arquivo pessoal do autor.

A história se revolve. Ao invés de encerrá-la em ciclos, tomando-a por sua característica repetição e mesmo qualificá-la de farsa, prefiro admitir que apesar dos elementos estarem majoritariamente já dispostos, revezando seus comportamentos, intensidades e acidentes, cada nova combinação entre agentes oferece um novo acesso a velhos problemas. Agora, é a história da arte que tem mais uma chance de vigorosamente atualizar o papel de suas instituições e rever sua contribuição na atroz racialização epistêmica do mundo. A via de acesso a que me refiro se dá através da mobilização mais recente e apesar da pandemia, performada pelo movimento antirracista Black Lives Matter². O assassinato por sufocamento de George Floyd, cidadão negro morador de Minneapolis, Estados Unidos, executado sob a tranquilidade sádica de um policial branco, viralizou nas redes sociais e na grande mídia, causando protestos massivos que de início se disseminaram por todo os Estados Unidos, seguido de uma onda em diversas partes do mundo. Nesta luta antirracista, que se confunde com as políticas decoloniais, dada a genealogia entrecruzada de ambas as causas, as manifestações contraviolentas incluíram a derrubada de diversas estátuas, várias das quais em homenagem a Cristóvão Colombo e outros escravagistas heroicizados como desenvolvimentistas alheios aos crimes cometidos contra os povos originários e a humanidade negra. Como artista e teórico da performance, me pergunto: como essa ação se inscreve e, portanto, reescreve a história da arte?

2 Black Lives Matter é um movimento antirracista, sem liderança centralizada, e que se tornou mais pelo uso da disobediência civil nas lutas contra a violência policial racializada. Para saber mais acesse: https:// blacklivesmatter.com. 
Como podem as instituições de arte responder ao chamado deste ato de fala?

A tomar pelas discussões e os rituais que rondam a qualidade figurativa das estátuas, faz-se manifesto o quanto sua presença concreta não só evoca um passado biográfico como positiviza os feitos de seu representante. A vida pode ser contraditória, mas uma estátua, erétil como é, se ergue como uma afirmação. Num torno foucaultiano, podemos pensar que mais do que prover referência a um dado histórico datado, uma estátua data sempre como a história enquanto discurso é contada. Enquanto as últimas décadas têm disputado os protagonismos e as epistemes eurocentradas, chama atenção quando a brutalidade arcaica do racismo retorna com seus símbolos mais ferrenhos. Um sinal recente disso aconteceu em agosto de 2017 , quando o pedido formal de retirada da estátua de um general confederado ${ }^{3}$, trouxe às ruas de Charlottesville, Estados Unidos, membros da Ku Klux Klan com seus capuzes brancos, paus e tochas, em marcha e sob aval da Casa Branca ${ }^{4}$. O grau de exposição dos supremacistas em seu prazer visual racista é, no mínimo, um alarme do quanto essas estátuas e as perspectivas históricas que elas representam são uma usina produtora de imaginários da branquitude, que como sabemos é uma metafísica sempre pronta a encarnar nos mais diversos corpos e comportamentos.

Colocado de outra maneira, Achilles Mbembe (2018) define essas estátuas como uma fusão de objetividade, subjetividade e mortalidade, e reafirma o quanto sua propriedade totêmica insiste em assombrar as desigualdades sociais do presente com os protagonistas do passado, elas sãos os:

[...] restos do potentado. [...] São os signos da luta física e simbólica que essa forma de poder teve que travar com o colonizado. Sabe-se que para ser duradoura, qualquer dominação precisa não apenas se inscrever no corpo dos seus súditos, mas também deixar marcas no espaço que eles habitam e traços indeléveis no seu imaginário. (MBEMBE, 2018: 225)

A insurgência em série contra monumentos em homenagem à exploradores e expropriadores, que acontece mundo afora, mas não no Brasil ${ }^{5}$, atua justo sob essa lógica que afirma o caráter trágico, e contra heróico da história colonial mundial. Lembremos que a colonização é um aparato violento de corte que desorienta e fere a forma com que as relações antecessoras se teciam, inviabilizando qualquer retorno. Sob o gesto deliberado de corte, a origem deixa de ser indigenista ${ }^{6}$, para se tornar uma ferida. Franz Fanon (2008: I09, grifo meu) nos alertou que "[...] qualquer ontologia torna-se irrealizável em uma sociedade colonizada e civilizada". A precisão de sua fala é referenciada pelo esquema histórico-racial que torna a experiência do negro sempre como "sendo diante do branco" (FANON, 2008). A noção de ser para o outro se racializa e se

3 O estado da Virgínia aderiu brevemente à confederação, cujo movimento separatista estava diretamente ligado à manutenção da escravidão nos estados membros.

4 Dias depois, outra marcha desta vez em reação àquele desfile macabro, terminou com um manifestante negro morto após ter sido deliberadamente atropelado por um supremacista branco. Fonte: <https:// www.npr.org/2019/06/28/7369|5323/neo-nazi-who-killed-charlottesville-protester-is-sentenced-to-life-in-prison? $\mathrm{t}=|60016| 254308>$. Acesso em: I 4 set. 2020.

5 Até o fim da escrita deste texto, em agosto de 2020, as reações ao estatuário urbano heroicizando o colonizador, permanecia sólido sobre seus pedestais, a exceção sendo as intervenções sofridas no monumento aos bandeirantes nas proximidades do Parque Ibirapuera em São Paulo. Mas, mesmo nesse caso, a atuação foi inscrita de dentro do terreno da arte e teve autoria nominável, visto que foi performada pelo artista plastico Helio Menezes em parceria com Denilson Baniwa, entre outros. Importante como foi, essa ação ainda assim se difere de um levante da multidão.

6 Como nos lembra Walter Mignolo (2019), Indígena é aquele se origina de um país, um nativo. 
hierarquiza, especialmente, quando o quem detém o poder estrategicamente constrói os arquivos que a fundamentam.

Ao se referir ao termo arché, Jacques Derrida (200I) nos mostra que início e comando são dois significados que se confundem neste radical. A colonialidade, certamente, fez uso dessa convergência de sentidos, ao construir um arquivo próprio, territorializando, datando e renomeando espaços, que sob tal métrica, antes não existiam. Assim, paradoxalmente, o que se configura como início é uma perda com os laços de origem, um convívio trágico com a história de nossa formação social diaspórica que se dá também sob a imagem do que Denise Ferreira da Silva (2017a) chamou de dívida impagável.

Essa dívida é de ordem econômica, diante da impossibilidade de quantificar a expropriação do trabalho escravo e a territorialização das terras nativas, mas também ética - na medida em que cria uma pretensa ordem de mundo (SILVA, 20I7a: 21). Impagável, a dívida se perpetua, perpetuando também nossas relações em dívida. De dentro deste breve diagrama de teorias e percepções que nos ajudam a entender a engenharia colonial e racial, pergunto: como heroicizar o que nos mostra como corte e perda, ferida e dívida?

Ao contrário do que parece, a ação de desfigurar essa dimensão sem volta que nos constitui, reconfigurando-a como motivo de orgulho em estátuas heróicas sobre pedestais hierarquizantes, se torna menos um ato de exposição do que de obliteração de nossa história. Mas o que fazer, na medida em que não há retorno possível a uma origem perdida e que tampouco se elimina um corte com novos cortes, sob o risco de repetir-se os mesmos atos que repulsamos, e ao fazê-los fortalecer a metafísica a qual justamente queremos enfraquecer? Como agir sobre esse corte que nos constitui e que é trágico porque indelével? Essa pergunta me orienta no movimento decolonial, visto que desfazer as relações coloniais é menos um retorno a sua anterioridade do que uma forma de seguirmos adiante. Ou, como nos diz Denise Ferreira da Silva (2017a), é necessário performar uma inversão nas flechas do tempo, encontrando relações entre os atos que não sejam meramente encadeamentos sequenciais e que, fora desta linearização, force a história a repensar suas bases epistêmicas e sua participação nas opressões racializadas.

Figura 2 - DeVolta\#I (2020), performance do Diambe Silva. Um círculo de roupas encharcado de líquido inflamável é ateado em fogo por dois performers. A estátua de D. Pedro I já cercada por grades de proteção é agora encurralada pelas chamas. Praça Tiradentes, Rio de Janeiro, RJ

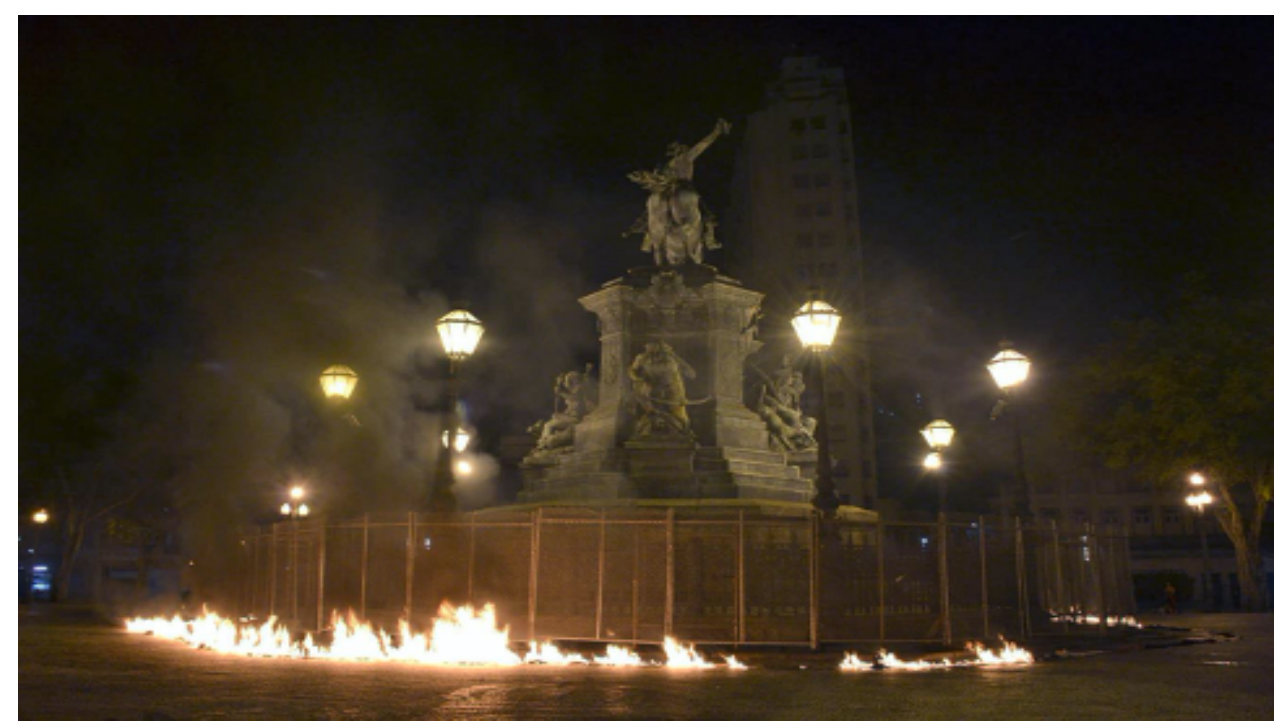

Fonte:Arquivo pessoal do autor. 
Essa revisão histórica dos acontecimentos que aponto aqui sob o espectro dos estudos de Pretitude ${ }^{7}$, faz-se necessária para visibilizar a violência a qual a humanidade negra e os povos indígenas foram e são submetidos nas Américas, tanto quanto para perceber que o racismo é prioritariamente um problema da branquitude e que mesmo fazendo mal aos brancos, nós relegamos nova e recorrentemente seu combate àqueles a quem racializamos. Dentre os inúmeros motivos aos quais devemos nos voltar à experiência corporal e fenomenológica da humanidade negra, o que quero chamar atenção é para o fato de que essa condição ontológica irrealizável não deixa nenhum dos povos incólume, mesmo os que criaram essa episteme racial para aparentemente saírem vencedores.

Os movimentos antirracistas, por sua vez, são movimentos libertários. Sua lógica está já explícita numa carta publicada em 1963, quando James Baldwin escreve a seu, também James, sobrinho. Entre acolhimento e reconhecimento de violência, tão presente quanto ancestral, Baldwin coloca o que diz ser o centro de sua escrita, o fato de que " [os brancos] estão presos a uma história que eles não entendem; e até que eles a entendam, eles não podem ser libertados. Eles tiveram que acreditar, por muitos anos e por inúmeras razões que os homens negros são inferiores aos homens brancos.”. E sem poupar nem mesmo os brancos conscientes diz ainda "muitos deles, na verdade, sabem que não é assim, mas, como você descobrirá, as pessoas acham muito difícil agir de acordo com o que elas sabem" (BALDWIN, 1963). O tom altamente afetivo de uma escrita que é política, mas que fala para os seus e entre os seus, reenquadra a maldade sob a qual a humanidade negra está submetida há pelo menos cinco séculos, como uma ingenuidade intelectual da branquitude nutrida por um imaginário de poder, que ao invés de ter vencedores, torna-nos, os Brancos, vítimas de seu próprio sistema opressor, mesmo se esse sistema faz com que os negros sofram ainda mais.

Escrita com sagaz clareza e como um aviso, uma atitude antirracista se torna justo aquela que manifesta o quanto o circuito de opressão não libera ninguém, nem mesmo a quem oprime, e que a opressão come por dentro, formando o caráter, ou ainda mais eletrizando e estressando o sistema nervoso, acidulando os estômagos, assombrando em paranóias, adoecendo-nos enquanto sujeito e sociedade (FOUCAULT, 1977). A fala de Baldwin em nada atenua os crimes de racismo, nem os desculpas, mas adequa esses atos como fracos apesar de e justo por serem violentos. Esta lógica reconhece e redimensiona o apego ao poder e neurose hierárquica racial. Mas a questão perdura, como os arquivos coloniais e em especial as instituições que historicizam e geolocalizam a arte são capazes de perceber sua criação e contribuição nessa episteme racial?

Em As estátuas também morrem (1953), filme-ensaio de Alain Resnais e Chris Marker, o furor de arquivo dos museus é colocado em xeque, como uma forma não só etnicista, como antipreservacionista e mortal. Os diretores se voltam à aquisição de estatuário negro por museus europeus em sua prática colonial disciplinante e colecionista da diferença. Embasados pela função das estátuas de preservar o corpo morto através de sua imagem, eles afirmam essa dimensão ritualística do figurativo, arruinada quando uma estátua é deslocada

7 O referido termo é a tradução mais próxima do inglês Blackness, que Fred Moten (2003) define como uma condição de vulnerabilidade à qual as pessoas negras têm mais acesso. $O$ cuidado em definir pretitude como uma condição vem justamente da necessidade de desnaturalização da racialização, como uma forma de ordenar o mundo e hierarquizar suas diferentes populações. Além disso, uma vez que negritude é um movimento francófono de extrema importância à literatura e ao ativismo negro (Aimeé Cesaire e Franz Fanon são dois de seus protagonistas), torna-se de suma importância construir uma terminologia que preserve a memória e a ação desse movimento. 
e plantada num museu. Deslocado de seu contexto, é ali que o objeto de luta contra a morte, ou de perseverança apesar da morte, morre também. Agir de forma alheia a essa dimensão imaterial da estátua, inibindo seu caráter ritualístico para priorizar uma visão plástico-simbólica, ultrapassa a lógica de saque. Reduzido ao prazer visual de sua exposição, o objeto é fetichizado e logo apto a inserir-se no capitalismo de mercado, impactando não apenas a obra aprisionada no museu, mas o próprio contexto que o produziu em primeira mão. Novamente, a prática colonial se confunde com a racialização ao ferir formas de vida anteriores a sua imposição epistêmica.

O colecionismo que advém do saque, constrói ele próprio uma estética e um desejo que transfere o ritual metafísico de produção daqueles objetos para a atividade econômica. Assim numa perda clássica de aura, estabelece-se uma produção massiva de arte étnica, descaracterizando sua cultura ancestral, porém, pronta a saciar seus consumidores brancos. A violência primeva do saque se estabiliza numa segunda violência, a do consumo. Não apenas mata-se uma estátua levando-a ao museu, quanto aborta-se tantas outras.

Figura 3 - $\mathrm{Fa}(\mathrm{r})$ dado (20l8), performance de Elilson. Centenas de envelopes são arremessados do alto de prédios a uma multidão de pedestres. $O$ conteúdo do envelope aproxima a ditatura militar ao Brasil atual ao justapor o pronunciamento de Marcio Moreira Alves contra as Forças Armadas a um cartão de acetato reflexivo onde se lê a pergunta que o estudante Marcos Vinicius fez antes de morrer baleado pela polícia militar carioca:"Ele não viu que eu estava com roupa de escola, mãe?"

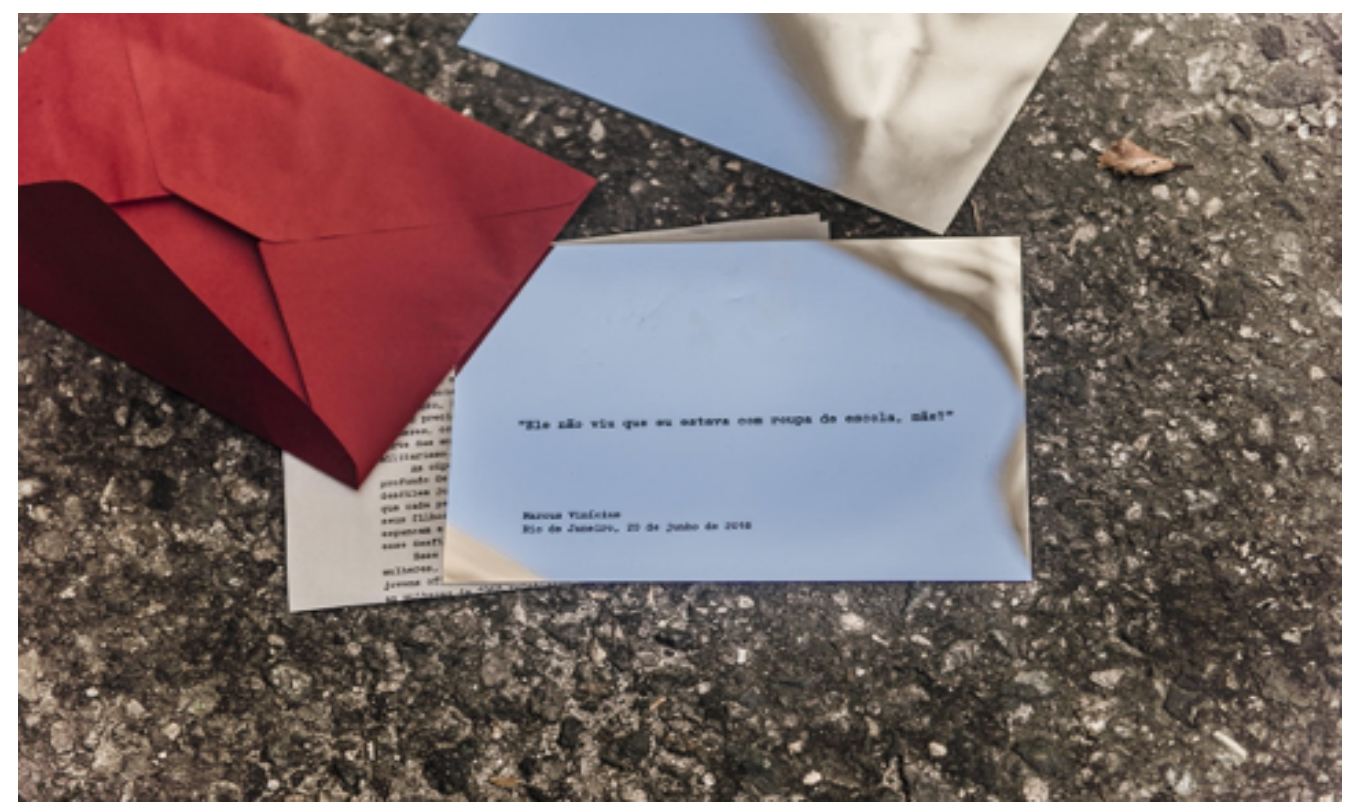

Fonte:Arquivo pessoal do autor.

Se Alain Resnais e Chris Marker destrincham a norma histórica da relação dos museus com o estatuário africano, o que sugiro é que há agora com a ação de derrubadas do Black Lives Matter uma outra forma de a arte estatuária negra entrar nos museus históricos, antropológicos e do homem, e sob uma complexa noção de autoria.Tal qual a Monalisa de Bigode e a Monalisa barbeada de Marcel Duchamp, sugiro que aquelas estátuas sejam, agora, percebidas como produto das intervenções performadas coletivamente pelos manifestantes antirracistas. Interessa, pois, como essa luta que passa pela representação, mas também a ultrapassa, constrói outras possibilidades de relação das instituições de arte com o arquivo colonial, tensionando a proximidade entre perseverança e preservação, redistribuindo a negociação entre forma e força, redesenhando o arco entre o figurativo e o performativo, e entre autoria, propriedade e 
coletividade. Lembremos que na medida em que suas ações são libertárias, ao reverberarem-nas são as próprias instituições de arte que atuam descolonizando a história de sua criação. Dentre elas os museus, instituições historicamente inventadas sob uma metafísica da noção de propriedade e que marca a diferença pela via da colonização.

Diante da onda de protestos antirracistas, Marvin Rees, prefeito negro da cidade inglesa de Briston, sugeriu que a estátua de um traficante de pessoas escravizadas derrubada e avariada pelos manifestantes seja realocada no museu, porém, preservando-se todos os vestígios do que acarretou a sua queda, incluindo-se as cordas nela amarradas ${ }^{8}$. A nota oficial afirma que a remoção da estátua, arremessada num rio, se fez necessária especificamente por conta do fluxo de navegação. Esse desdobramento não me parece trivial. Aproveito o momento em que um museu municipal abre espaço para essa ação do Black Lives Matter, para abrir também uma fenda na história da escultura. Sugiro que essa acolhida institucional à queda performa uma nova camada do que consideramos a desmaterialização da obra de arte. A diferença, porém, é que agora a repulsa ao figurativo e seu subjugo à ação está racialmente comprometido.

Inicialmente, Lucy Lippard and John Chandler (2013: I53) definem a desmaterialização como parte de um processo a que chamam de arte conceitual "que enfatiza o processo de pensamento." O engajamento na ideia é tamanho que se perde o interesse no objeto, tornando-o de fato obsoleto. Ao contrário, nestes exemplos antirracistas a que me refiro, a obsolescência do objeto é uma meta e só acontece devido a muito esforço coletivo. $O$ objeto-estátua como nos alertou Mbembe é também carregado de subjetividade biográfica. Através da ação árdua do Black Lives Matter, essa subjetividade biográfica escravagista perde espaço para a performatividade do coletivo antirracista. Desta maneira, me parece notório que neste embate, o que se deve fortalecer é a migração de um indivíduo heróico para a força da multidão e, portanto, que os museus devem se preocupar mais com a queda do que com as estátuas. Se como nos dizem Lippard e Chandler (2013), os artistas minimals se detiam sobre o conceito e perdiam o interesse pela evolução física do trabalho muitas vezes industrial e seriado, aqui a força física é a que se faz potencialmente deflagradora de vários outros conceitos e ideias.

Mas ainda assim poderíamos vincular a derrubada das estátuas a um segundo acesso à desmaterialização da arte, aquele ao qual Lippard e Chandler (ibidem: I53) se referem como sendo "arte como ação", ou seja "quando a matéria é transformada em energia e tempo-movimento". A história da escultura, certamente, poderia ser contada como uma história de afastamento da estátua. A sua desmaterialização surge num arco progressivo que repulsa a imitação e a mágica e que, em última instância, trabalha abstração e liberação da ideia (ibidem). Mas aqui, a forma que a desmaterialização ruma à performance e a seus performativos se dá senão sob uma decadência forjada da matéria, cuja propriedade histórica nos lembra que sua materialidade não é só física, mas também representativa. A especificidade desse processo de decadência não se resume a uma degradação natural do tempo, nem deve ser naturalizado, porém, percebido e internalizado como uma inscrição bastante direta e política de des-

8 Ler mais sobre em: <https://www.bbc.com/news/uk-england-bristol-53004748> e <https://www.nytimes.com/2020/06/23/style/statue-richmond-lee.html?auth=login-google>. Acesso em: 08 ago. 2020. 
figuração. Seu compromisso não é o de se desenvolver ao abstracionismo, mas antes se regular na própria ação de desfigurar, uma ação tão física tanto quanto reformadora do imaginário e das subjetividades que aquelas representações por ventura estimulam. Sob essa dupla camada de materialidade, física e simbólica, desmaterializar se torna a persistência no próprio ato de desfazer, entretanto, atento às proposições que daí provenham.

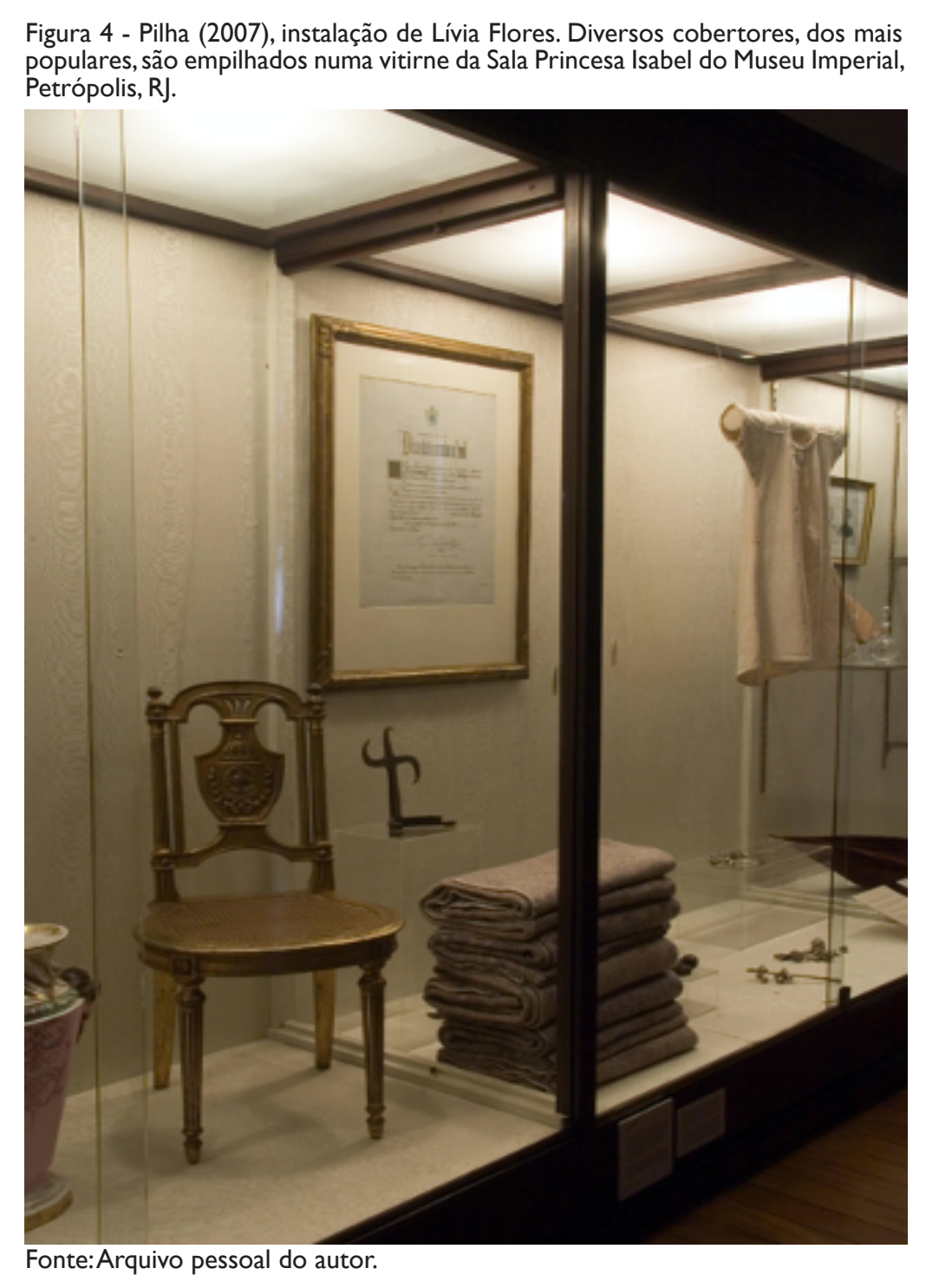

Assim, ao se rebelar contra os artefatos figurativos dos arquivos coloniais, o Black Lives Matter, finalmente, propicia uma virada performativa às estátuas, desnaturalizando e inviabilizando sua representação visual individual e passíveis de existência somente em relação aos vestígios táteis que as deformam. Sendo não apenas a imagem de um herói colonial, como também, o arquivo do heróico no colonial, a estátua se torna algo a ser derrubado, atingido e mantido se e sob a decadência a que sua matéria foi submetida. Logo, o que persevera não é uma biografia, mas a decadência de sua figura. A desfetichização da sua forma monumental, torna este tipo de estatuário o pivô racial da crise de representação. É essa força estética de crise que deve prevalecer sobre as formas de poder que insistem em retornar, mas que não devem permanecer.

É por isso que não podemos encerrar a discussão de desmaterialização 
das estátuas na definição de arte como ação conforme proposta por Lippard e Chandler (20l3), porque se fazemos isso, perdemos justamente o acesso a pensar a desmaterialização no que essa proposição estética reconfigura as relações histórico-político-raciais. Como vimos, a obsolescência do objeto minimal em muito difere da decadência do figurativo no estuário supremacista. Enquanto no primeiro caso, o objeto é índice de um conceito, no segundo a obsolescência se torna uma meta. Enquanto a execução do primeiro é eminentemente industrial, no segundo caso, o objeto é arquivo de uma disputa corporal intensa e duradoura. A decadência é uma forma lenta de queda, e essa forma que muitas vezes é naturalizada no abandono, aqui se faz deliberadamente como uma forma de preservação das forças que a deflagraram. A ruína que dela deriva, quero crer, não é um símbolo de conquista, mas do ativismo antirracista que não se interessa em ocupar os mesmos postos racializados de poder, mas justamente torná-los obsoletos ao ponto de inviabilizá-los.

Ao serem assimiladas no museu formalmente danificadas e em função de conservarem os vestígios das forças que agiram contra àquelas figuras, estas obras se tornam obras sem artistas. Ou pelo menos sem autores que se territorializem no terreno da arte. A capacidade de agência desse movimento adiciona assim também sua singularidade ao binômio arte-vida, especialmente por ser performada por manifestantes que atuam no âmbito da arte, porque lutam pela própria vida. Black Lives Matter é um movimento, ele mesmo uma ideia, e cujo termo Matter faz com que o corpo negro importe por ser valorizado, mantendo-se vivo, mas também propagando sua fenomenologia e instituindo a metafísica da pretitude. Entre atos físicos e de fala, essa virada performativa reinsere a estatua na lógica processual, no mesmo passo em que expõe a história como materialidade discursiva apta a ser mexida, escrita, e reescrita. Mas, se forma é também conteúdo, reescrever não e só uma tarefa de fazer valer outras narrativas, senão o conjunto de todas as operações e experimentações estéticas que fazem-nas existir. Outrossim, musealizar a queda, é a forma ética, a qual o museu tem também de reescrever sua própria história, que é senão aquela que se confunde com a história que ele guarda.

Figura 5 - Turvações Estratigráficas (20II), Exposição de Yuri Firmeza no Museu deArte do Rio. $\mathrm{Na}$ exposição de abertura do Museu, inaugurado como abre alas da série de reurbanizações radicais implementadas na zona portuária carioca, $\circ$ artista translada para a galeria entulhos de casas populares da vizinha comunidade do Morro da Providência. Sob muita resistência, as casas foram demolidas e seus moradores realocados para que no local se criasse um teleférico e um mirante turístico na região.

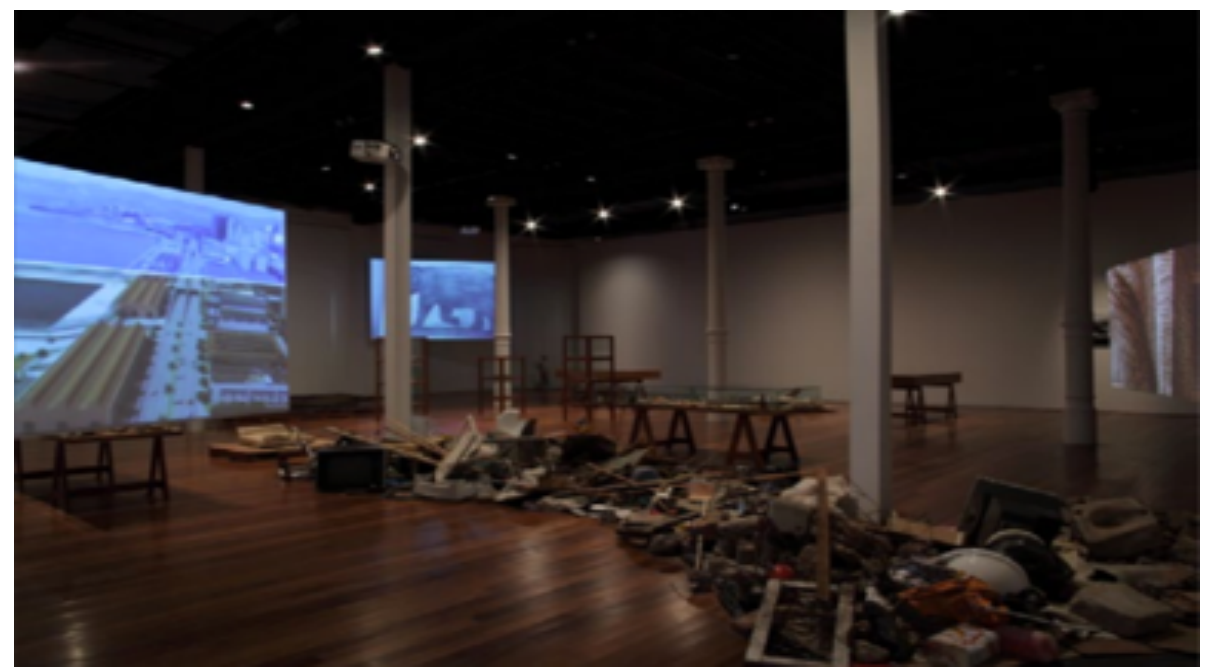

Fonte: Disponível em: <http://museudeartedorio.org.br/programacao/yuri-firmeza-turvacoes-estratigraficas/>. Acesso em: 15 set. 2020. 
No que diz respeito à ética museológica desse deslocamento de obras, é importante que fique claro que migrar estátuas de supremacistas para o espaço fechado e controlado, menos protege as estátuas do que expõe os museus! Como levar as estátuas ao museu de forma que a força antirracista que a derrubou e deslocou não seja novamente apagada? Madeleine Odent, curadora de outro museu municipal, também, no Reino Unido, após ver as imagens da estatua caída em Bristol, instruiu nas redes sociais que "da perspectiva de preservação de arte, não há qualquer problema em jogar tinta nos memoriais de racistas genocidas! Tinta é fácil de ser removida. $O$ que seria absolutamente uma vergonha é se jogassem produtos comuns de limpeza doméstica, esse sim capazes de causar danos irreversíveis ao bronze," já que "[...] ninguém perceberia a reação química até que fosse tarde demais para revertê-la". Apesar de irônica, a desmaterialização se torna o objetivo a ser preservado.

Talvez cientes que ao mexer neste tipo de matéria estatuária, não se mexe em somente uma estátua, mas no todo de sua categoria e em todos os agentes que de alguma forma nela interferem ou legitimam, podemos sugerir que algumas perguntas reverberam e reverberarão por muito tempo através desses atos: como agir na desracialização das coleções históricas museológicas? Como afirmar o caráter performativo e não neutralizado dos arquivos e, justo por isso, comprometer-se com uma história revista pelos preceitos antirracistas? Uma história que, longe de ser apagada, é revista imbuída de certo grau de autorreflexividade, o que necessariamente passa por afirmar sua episteme branca. Neste sentido, como garantir que a instituição que certamente esta atrelada a atividades formativas e educativas, esteja também ciente de que por seus feitos e efeitos são dotados de um constitutivo sensorial, afetivo e perceptivo que forma os sentidos tanto quanto os discursos, o imaginário tanto quanto o simbólico? Como garantir que as estátuas que ora chegam aos museus tencionem com todas as outras presenças históricas? Como, do contrário, permitir que essa estátua derrubada e avariada passe do orgulho à vergonha, de sua forma figurativo-biográfica à força performativa de multidão e que, portanto, reverbere a metafísica não mais da branquitude, senão da pretitude?

\section{III}

Figura 6 - Desmonte (2018), vídeoperformance de Felipe Ribeiro, parte integrante da série Ações de Revirada. Desfazer se torna o conceito base de confrontar os agenciamentos da branquitude num país de herança colonial e relações escravocratas. Em Desmonte o corpo branco deitado sobre falésias de argila pressiona o solo para afundar, mas ao invés de aderir, experimenta a queda e o colapso.

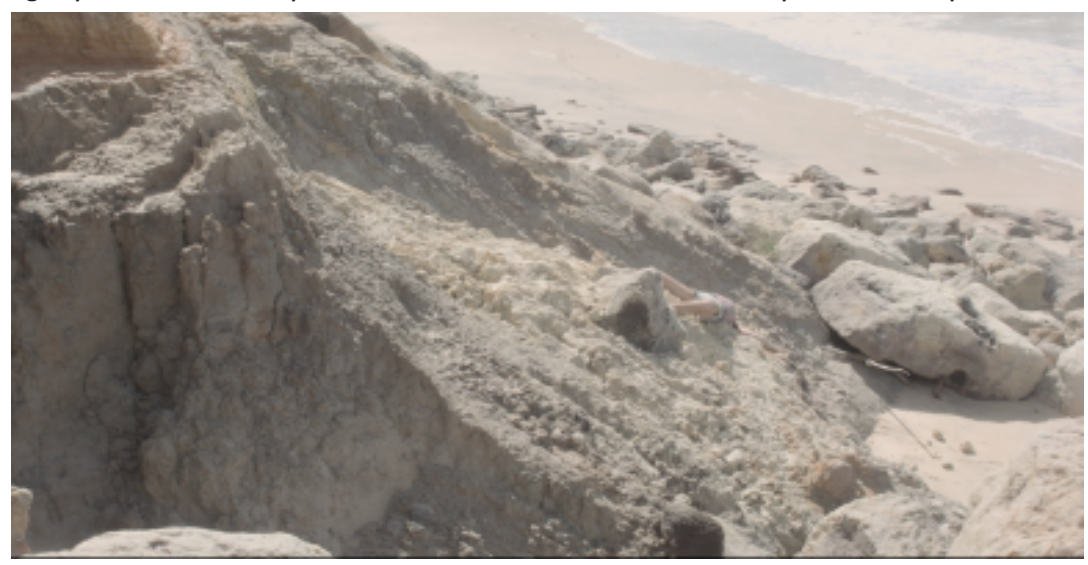

Fonte:Arquivo Pessoal do Autor.

9 Disponível em:<https://www.theartnewspaper.com/news/curator-investigated-for-tweets-on-damaging-bronze-statues>.Acesso em: I 4 set. 2020. 
Musealizar a queda é também assegurar algumas dimensões: a primeira, por um lado a queda é uma força imediata perpetrada por um coletivo nomeável, porém, inidentificável, pois sempre pronto a aparecer em diferentes lugares, simultaneamente e em diferentes formações, de pessoas que pressionam o objeto até que sua instabilidade seja tamanha que ele não seja capaz de se sustentar em eretilidade e caia. Há aqui uma queda de braços, operada por uma força brutal, que é a dimensão mais física que a queda pode ter. Mas, ainda assim é um tanto redutor bastá-la por sua fisicalidade, desconsiderando o acúmulo de situações, que certamente a compõem. Ainda que inscrita numa prática direta, esse movimento de derrubada não se configura como uma casualidade impulsiva, mas como uma resposta a um plano continuo de violências raciais. Daí que não é justo adjetivá-lo de violento, senão de contra violento. Este último termo deixa claro que sua ação incisiva vem de uma provocação e que a derrubada das estátuas opera uma reação, não devendo ser analisada como um evento isolado. Não obstante, os atos vieram também muitas vezes acompanhados de discursos contextuais e diálogos públicos, nos quais manifestantes reafirmavam e fortaleciam suas premissas. Tanto a queda quanto a estátua são constituídas pelo arco da história, entre atos, fatos e assombros metafísicos.

Logo, reduzir uma disputa política ao imediatismo impulsivo é reduzir seus intuitos à brutalidade. De verdade, esta tem sido a estratégia supremacista branca. Colapsa-se a escala das disputas aos acontecimentos mais presentes, desvinculando-os de qualquer relação ou encadeamento com o passado e abdica-se de sua notoriedade política em prol da personalização dos dilemas. O contexto e as condições que o compõem deixam de fazer parte da situação, segue-se na ilusão de que todo evento é o grau zero de si e se resolve no mesmo aqui e agora que o gera. Com os problemas solucionados nas mesmas circunstâncias que o criaram, eventuais traumas constituem quando muito dramas pessoais, sem jamais se inscreverem na história e prefigurarem suas políticas. Segue-se, então, a vida em sua versão mais simplista, desconsiderando-se as condições que geraram os diferentes sujeitos racializados, forjando-se uma pretensa e incondicional igualdade de oportunidades.

A estratégia supremacista branca de um passado que passou e de um presente de sortes, ao que tudo indica vai mesmo na contramão das manifestações do Black Lives Matter. Como um movimento de repulsa, o antirracismo se configura pela persistência, pela repetição e como práticas de reeducação. É, portanto, um movimento de mediação, que deixa em descrédito qualquer resolução magicamente imediata, ciente que está de que a redução do preconceito a eventos isolados é inclusive a forma que se tem de propagá-lo. O racismo é a soma de todos os crimes que o mantém ativo e por isso a persistência nessa luta tão urgente, quanto fadada a ser longa.

Esta é a segunda dimensão de experiência de queda que proponho: o ato deliberado de derrubar não é uma experiência que se basta na fisicalidade, mas cuja sensação é necessariamente atravessada por qualidades históricas. Me interessa aqui como esse ato elabora o fato. Como a experiência em seu campo de imanência é percebida não apenas pelo que se faz atual, mas por todos os virtuais que tal ato faz orbitar. A série de derrubadas é o atual que renova os virtuais que a orbitam. E se concordamos com Gilles Deleuze (2005; 200 I: 30), o campo de imanência é primordialmente formado pelos virtuais, pelos devires entre o que já não é e o que ainda não foi. No entanto, como o espaço intermediário, esse campo do entre só existe em relação a pontos demarcados e sua existência está assim condicionada ao comportamento dos atuais. Os mesmos 
que atualizados geram os discursos históricos, que por conseguinte são atualizações compostas de materialidade discursiva e, portanto, novos geradores de virtuais.

Faço essa digressão filosófica aqui para lembrar-nos que seria também redutor se relegássemos a história como um discurso exclusivamente transcendente ao ato e, portanto, externo à experiência. Como um atual que se firma e define $o$ ato, a história se distancia da experiência só para retornar a ela e engajar outros devires. $O$ discurso histórico é portanto um agente produtivo que não se basta na abstração da experiência, assim como o racial, o colonial e o capital (SILVA, 20I7a) tão pouco se bastam em abstrações, mas geram efeitos e devires muito concretos. Colocado desta maneira talvez pareça óbvio, mas o óbvio deve ser por vezes refraseado: a imanência é um plano que não se confunde com ações imediatas. $O$ imediato se faz por atualizações, a imanência pelos virtuais. A composição de seu plano não se basta nas ações, mas delas derivam e por entre elas atravessam, visto que cada atualização reconfigura os virtuais que orbitam os atuais.

Em sua composição de material mineral e discursivo, a estátuas carregam história consigo e a história do que pela história deviu. É nesse sentido que o encadeamento cronológico de ações e reações é apenas mais uma das linhas que tecem um plano, amplo, horizontal, vazado e cheio de relevos. Se voltamos a Mbembe, lembramos que o potentado bem sabe que para manter-se virtualmente é necessário visibilizar sua herança. Ao se derrubar uma estátua explicitando-se sua consistência política, fragiliza-se uma usina de performativos supremacistas, mesmo se outros venham porventura a surgir. Impregnar a estátua de queda é gerar outros performativos. A imagem caída do homem branco, esse ato de levar o homem ao chão, de inserir um objeto sustentado pelo plano de transcendência da história de volta ao solo, performando o movimento que está na base etimológica da palavra humilhar (voltar à terra) é, portanto, um movimento de reverter o orgulho branco em vergonha nacional.Vergonha essa que se explicita, quando mãos negras empurram a estátua, num levante que encontra nos eventos contemporâneos reminiscências de encadeamentos históricos que insistem num retorno, e que vê na necropolítica tátil de um joelho branco sobre um pescoço negro as mesmas relações de violência total que expropriavam o trabalho dos escravizados.

Mas, é a terceira dimensão da queda que essas derrubadas acarretam a que mais me mobiliza. Essa dimensão é por excelência difratada e aprendemo-la pelo viés dos estudos de negritude tal qual proposto por Denise Ferreira da Silva. Aqui derrubar estátuas não se basta nos atos, nem nos fatos, mas abre-nos à prefiguração. É por isso que antes pensamos a queda por via de uma operação estética (desmaterialização), pois se essa atuação que parecia menor por ter sua relevância circunscrita à arte, ao que tudo indica é justa na estética que outros devires e entendimentos afloram. Se nas regras de funções diz-se do real em contraposição ao possível, assim como o atual está para o virtual, agora essa queda que atinge em cheio o material histórico constrói uma operação na qual o estético está para o impossível. O impossível não é o irreal, mas aquilo que, por não se opor ao real e do contrário compô-lo em sua especificidade, só se ativa como uma operação estética, sem tirar as questões raciais das proposições filosóficas chama atenção inclusive que o impossível venha de proposições da humanidade negra, aquela a qual Franz Fanon (2008) definiu como sendo de ontologia irrealizável.

Denise Ferreira da Silva $(2017 b)$ se refere à potência estética quando 
propõe que as ações se abrem elas mesmas em composições fractais. Formação geométrica não-euclidiana, o fractal nos oferece outros esquemas perceptivos, especialmente quando a lógica filosófica se ampara tão comumente nos sistemas matemáticos e físicos, organizando os saberes por topologias, formulações microfísicas, bem como diversas estruturas e formas geométricas. Silva coloca-nos, assim, a demanda de reformularmos os eventos cuja complexidade se atente à luz das escalas da física quântica e da geometria não-euclidiana, demanda esta que se aplica até mesmo a eventos tão newtonianos quanto uma queda.

Diz-se fractal quando o todo forma as partes, assim como a parte forma o todo, e a parte reflete o todo, assim como o todo reflete a parte. Essa duplicidade de gênese e reflexão e sua reversibilidade entre parte e todo, torna essa figura não somente de linguagem (visto que ela não se basta em metonímia), mas em composição de imagem. Aplicada aos eventos históricos, essa reversibilidade entre parte e todo se torna uma operação geométrica espacial, apenas no que o tempo se elabora, ele mesmo como espaço. Essa operação, assim, ao invés de sucumbir à sequencialidade da história, abre-a à concomitância dos tempos. Sob essa geometria, é a linearidade sequencial que se torna impossível. Todo evento é também espelho e ainda mais sob a perspectiva do espelho, é o evento o que the reflete. Gênese e reflexos são assim duas qualidades que apesar de distintas se tornam indiscerníveis.

Gilles Deleuze (2005) ja havia também pensado o par reflexo-criação, numa lógica coalescente do cristal, através da qual analisava imagens formadas nos interstícios descontínuos de determinadas narrativas cinematográficas. Ali imagens-atuais e suas imagens-virtuais, se intercambiavam fazendo com que virtualidades atualizassem e logo atuais se virtualizassem. Como uma primeira entrada, presumo que o fractal se comporte em similitude a essa imagem-cristal, porém agregando a narrativa de cortes e continuidades do cinema como um virtual que se atualiza na vida. Poderíamos encerrar prematuramente a questão dizendo que esse funcionamento entre repetição e diferença, é o comportamento iterativo dentro do qual os performativos operam. Mas, presumo que seja importante organizar esse par gênese-reflexo não apenas na concatenação dos sentidos, mas também nas sensações, nas formações pré-linguísticas, mesmo quando elas próprias são formadas pelo sentido. É por isso que concordo com Silva e Deleuze quando ambos, cada qual a sua maneira, tomam para si a necessidade de pensar o que seria essa operação estética geral, do cristal e do fractal. Deleuze o faz analisando e qualificando imagens, e Silva (20l7b: 59), por sua vez, recorre à intuição e ao poder de imaginação, através dos quais a geometria fractal se descola do acontecimento em sua fisicalidade e empiría estrita para imbuir-se da arte como um gatilho de desdobramento e mudança radical de relações ao produzir paradoxos inexplicáveis pela tríade separabilidade, determinação e sequencialidade ${ }^{10}$.

Sob a formação cristal, o atual e o virtual são duas faces entre as quais os acontecimentos se revezam. Nessa constituição, é a coalescência dos eventos, sua aglutinação uns nos outros, o que importa. A questão não é apenas que um evento atual reencena um anterior, mas que o anterior se faz de tal forma presente que a atual é capturado como sua imagem. Porém, ao refletir-se como imagem de um passado, é a história que é capaz de mudar como a percebemos e somos por ela afetada. À essa força especular, Denise Ferreira da Silva se refere sobre a potência de reverter a flecha do tempo, já que onde a concretude

10 Essa tríade é para Denise Ferreira da Silva o pilar do pensamento moderno e como proposto por Hegel e Kant. 
física se mostra inviável, a força estética toma-lhe o lugar da reflexão não como mera representação do que já se faz inviável, mas para difratar e poder disputar o futuro através de outros acessos.

Figura 7 - Monumento à voz de Anastácia (2019) de Yhuri Cruz. A noção de monumento aqui é redesenhada pela dimensão de seu alcance. Tomada pela força da pretitude, o monumental não é aquilo que desafia a escala humana, mas que aquilo que se espalha e contagia imaginários.

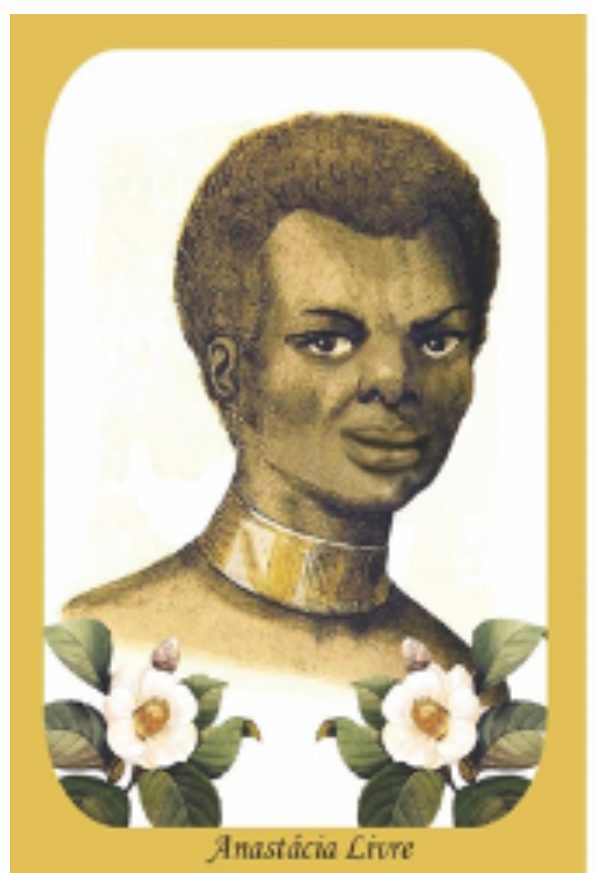

Oraça a Anastácia Livre

Fonte:Arquivo pessoal do autor.

É pois, sob a força especular dessas proposições, que as estátuas derrubadas nos abrem, e aos museus, uma teceira dimensão de queda, a da incerteza (SILVA, 20I7b: 6I). A operação estética singular de desmaterialização, no que ela atinge $\circ$ arquivo histórico, produz incerteza quanto a sua função primeva. Musealizar a queda é assim performar uma operação estética que faz tombar os próprios pilares dos museus, abrindo brechas libertárias que não apenas mudem a episteme sob a qual se elaboram os fatos, mas pressupondo uma operação estética elástica. Nessa operação experimental e sob a episteme da incerteza, o que acessamos como passado é percebido como o conjunto de tecnologias de apagamento do passado. Como experimentar o passado ciente de que sua constituição é também seu apagamento? Talvez seja somente sob essa incerteza estruturalmente bamba que as narrativas assertivas possam ser abdicadas em prol de se curvar à função de performar os arquivos existentes, de forma a que prefigurem os passados ainda por vir.

\section{Referências}

BALDWIN,James. Minha prisão estremeceu (Tradução de Teófilo Reis). In: The Fire Next Time. Nova lorque: Dial Press, 1963. Disponível em:<http://negrosblogueiros.com.br/teofiloreis/2016/traducao-minha-prisao-estremeceu/>. Acesso em: 7 ago. 2020.

DELEUZE, Gilles. A imagem-cristal In: . Cinema 2: Imagem-Tempo. São

Paulo: Editora Brasiliense, 2005. 
.Pure Immanence: Essays on A Life. Brooklyn, NY: Zone Books, 2001.

DERRIDA, Jacques. Mal de Arquivo: uma impressão freudiana. Rio de Janeiro: Relume Dumará, 200I [1995].

FANON, Frantz. Peles Negras, Máscaras Brancas. Salvador: Editora UFBA, 2008.

FLORES, Lívia. ARTEBRA: Lívia Flores. Rio de Janeiro:Automática, 2012.

FOUCAULT, Michel. Nietzsche, Genealogy, History. In: BOUCHARD, D. F (Org.). Language, Counter-Memory, Practice: Selected Essays and Interviews. Ithaca: Cornell University Press, 1977.

LIPPARD, Lucy; CHANDLER, J.A Desmaterialização da Arte. In: Revista a/e, n.25, UFRJ, 2013.

MARKER, Chris; RESNAIS,Alain. As Estátuas também morrem. Filme-ensaio, 1953.

MBEMBE,Achille. Crítica da Razão Negra. São Paulo: N-I edições, 2018.

MIGNOLO,Walter D.A Colonialidade está longe de ter sido superada, logo, a decolonialidade deve prosseguir. In: Serie Afterall, vol 2. São Paulo, MASP, 2019.

MOTEN, Fred. In the Break:The Aesthetics of the Black Radical Tradition. Minneapolis: University of Minnesota Press, 2003.

SILVA, Denise Ferreira da. A Dívida Impagável: lendo cenas de valor contra a flecha do tempo. São Paulo: Oficina Imaginação Política, 2017a. tica, 20I $7 b$

Sobre Diferença sem Separabilidade. São Paulo: Oficina Imaginação Polí- 